\title{
Energy storage station and Distributed power Synergistic dispatching management system
}

\author{
Peng $\mathrm{He}^{1, \text { a }}$, Kun $\mathrm{Li}^{1}$ \\ ${ }^{1}$ State Grid Qingdao Power Supply Company, Shandong Qingdao 266002, China; \\ ayjtxb@163.com
}

Keywords: Energy storage station, Distributed power, Synergistic dispatch

\begin{abstract}
Based on power grid dispatching automation platform, Establishing distributed resources cooperative scheduling management system, including wind power, biomass power generation, photovoltaic power generation and energy storage electric vehicle charging stations. The use of intermittent, renewable energy and between main and the energy storage device between the complementarity and collaborative, strengthen the ability of the power grid to absorb and consume intermittent power, reduce power grid load curve difference between peakand valley,improve the operation performance of power grid. This system has been applied in Shandong dispatch center.
\end{abstract}

\section{Introduction}

With the consumption of traditional fossil energy, the development and utilization of wind power and photovoltaic power is paid more and more attention, the current renewable energy is in a rapid development period. The renewable energy of Qingdao area contains wind power and solar power, its installed capacity has reached 500MW. Currently, new energy and distributed power in Qingdao City get large-scale development, the total installed capacity of distributed renewable energy in Qingdao is expected to reach 1300MW by the end of 2015. Large-scale wind power and photovoltaic power access to the grid, it is bound to bring threats and challenges for the power grid enterprise in management capabilities, grid-connected efficiency, power system planning, and scheduling.

Distributed power has imbalance in time and space and uncertainty of the power flow, causing the gradual weakness of the control of the power networks in the degree of logic analysis.

Because of the great influence of the time and space, main grid's difficulty of peak load shifting is increasing to a certain degree[1-3]. At the same time grid node voltage characteristics and protection devices will be affected. Since the traditional power grid is designed for the large-scale production, transportation, distribution and use of energy, it is not suitable for the large number of distributed resources accessing to grid. At present, the voltage level of the main grid which connects photovoltaic power generation are $10 \mathrm{kV}, 400 \mathrm{~V}$ and $220 \mathrm{~V}$. In the process of grid connected, the system has a lot of harmonic current, the current distortion rate is generally high [4]. Due to the instability of photovoltaic power generation, photovoltaic power generation can not access to the grid in the low demand of the grid, there will be the phenomenon of "disposable light". The power of photovoltaic power generation system is closely related to the temperature and light intensity, which means that it is affected by climate, thereby increasing the difficulty of main grid for renewable energy scheduling. The output power varies greatly with the real time of the climate, it increases the difficulty of system scheduling. In addition, when photovoltaic power generation accesses to power grid, there are a lot of technical problems in the voltage, reactive power control, power supply reliability analysis and electric energy metering. After a large number of photovoltaic power generation accessing to power grid, the original distribution network structure converts from the radial structure to the multi power structure, which requires a variety of protection and automation device to add or replace. Photovoltaic power generation accessing power grid is likely to have an island effect, in order to prevent the occurrence of this phenomenon, effective prevention facilities should be added.

Large-scale electric vehicle energy storage systems serve as a storage device of photovoltaic power generation, reducing drawbacks caused by the intermittent characteristics of photovoltaic power generation. The long-term storage of energy storage device increases the adjustable of 
distributed energy. Distributed power generation and the electric vehicle charging station connect to the distribution network, the dispatch center make a charging and discharging scheduling for the electric vehicle charging station, while the electric vehicle charging for electricity demand is met, it can increase the utilization rate of the distributed generation and reduce the peak and valley load slip, thereby increasing the peak-shaving capability of the main power grid. At the same time, the capacity of power equipment can not be added, increasing the load management [4]. Synergistic dispatch between energy storage power station and renewable energy generation by power grid has been a hot spot in the present development.

In this paper, synergistic dispatch management system of distributed power accessing to power grid is presented, based on the principle of synergistic dispatch, management and information transmission mechanism corresponding to the characteristic of synergistic dispatch objects are established, and finally synergistic dispatch management system is established, realizing the combination of photovoltaic power generation and electric vehicles, storage battery consumes photovoltaic power through synergistic characteristics, the electric vehicle charging demand is met, realizing peak load shifting of power grid and the safe and economic operation of the power grid.

\section{General Architecture of the System}

The synergistic dispatch system of distributed renewable energy connected to power grid is distributed resource monitoring and scheduling system, it provides a tool for operators to manage distributed power.

The energy storage station and the distributed power synergistic dispatch system establish a real time connection and obtain data by the interface of the system data platform. Data sources are mainly derived from the integrated data platform and CIM, the data of each system from data source layer is collected by designing and developing different interface adapters. History and real-time data are read dynamically. The data is extracted to the background platform. The various distributed renewable energy information accesses to synergistic dispatch system by building an integrated data platform. The information is displayed in the form of accurate reports by statistical analysis algorithms.

Photovoltaic power management respectively show grid voltage, grid-line information, photovoltaic station list, photovoltaic power station power proportion, power fluctuations and the current alarm.

\section{System Function}

In the case of large scale distributed power accessing to Qingdao power grid, the synergistic dispatch method for distributed power accessing to power grid is proposed, which is based on photovoltaic power generation and XueJiadao electric vehicle energy storage. A variety of resources are utilized efficiently and synergistically in the smart grid platform. Key features are the following sections.

\section{Monitoring and Management of Distributed Power Generation.}

For the distributed photovoltaic power system, the dynamic evaluation of users accessing to the photovoltaic power system is carried out in the integrated power factor, the harmonic content and the data quality.

1) 24-hour network analysis of maximum photovoltaic power, minimum photovoltaic power, photovoltaic power fluctuations of 5 minutes, 10 minutes and 15 minutes. Season and day prediction curve of photovoltaic power fluctuation is provided based on historical data.

2) Minimum and maximum power of photovoltaic generation in a day, peak valley difference of photovoltaic power, photovoltaic power output in the period of low grid power; peak valley difference of equivalent load; limited electricity generating by photovoltaic power, PV power fluctuations range in 5 minutes, 15 minutes and 1 hour. 

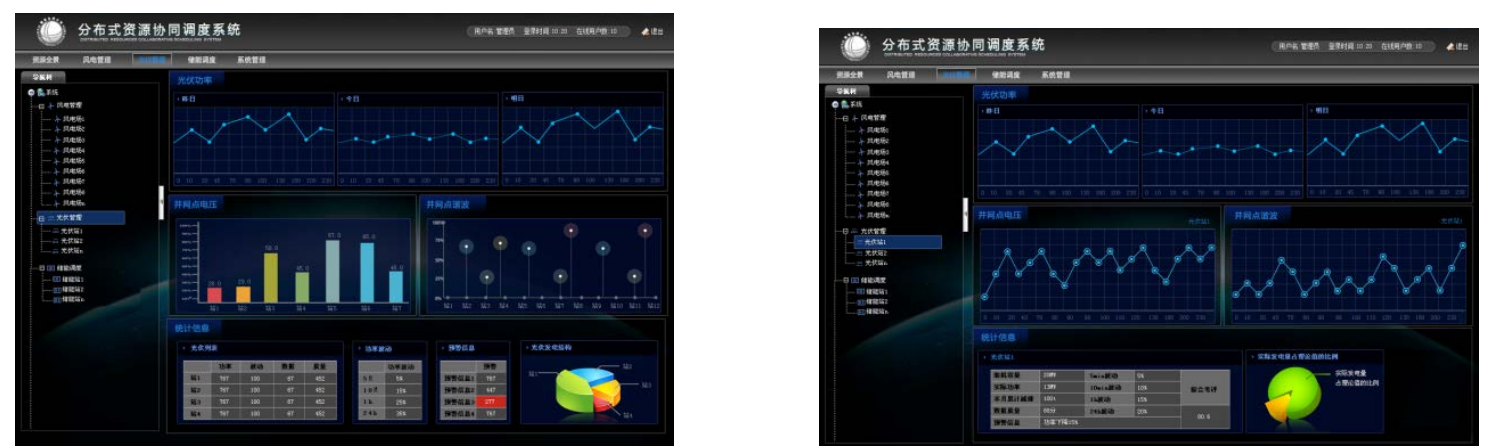

Fig.1 Qingdao total network PV monitoring management Fig.2 PV monitoring information

You can display the relevant data from the left side of the tree menu to view the power station name.

\section{Distributed Power Generation Scheduling Scheme Management.}

Scheduling scheme is based on the power forecast of the distributed power generation at 96 points per day, considering the actual operation of the power grid, the power generation plan for the distributed power generation is adjusted in real time.

Based on the study of energy in time and area, a model of multi resource complementarity in distributed power network as well as its measurement and evaluation system are proposed, and the conditions for generating complementary processes in different time and region scales are determined. For example, when a period of photovoltaic power forecast is greater than the forecast of a few days ago, the scheduling plan needs to be fixed, the new power will be allocated between the various energy storage stations.

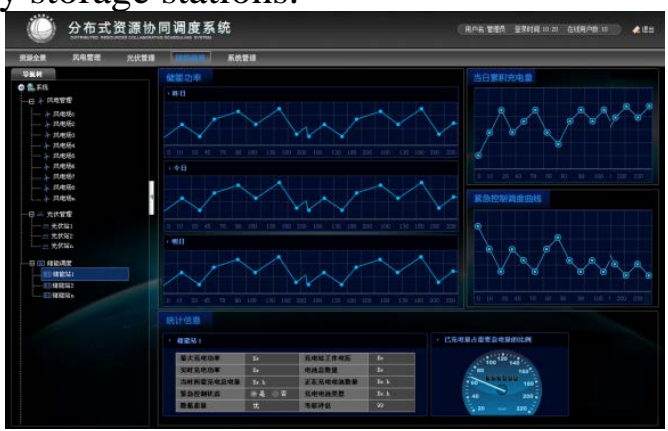

Fig.3 Storage Scheduling

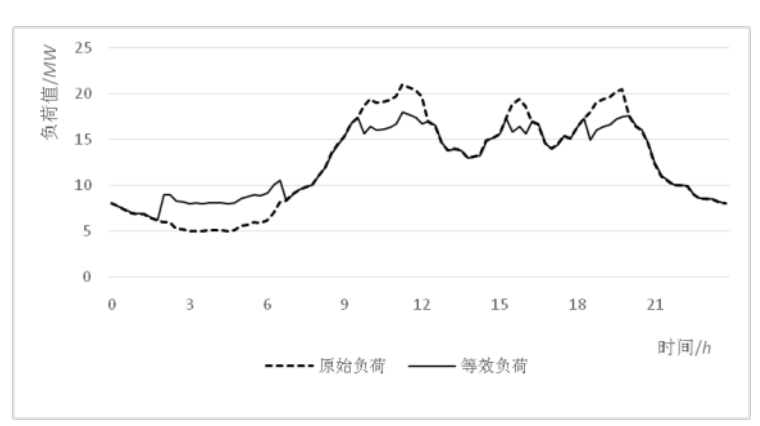

Fig.4 Effect diagrm of peak load shifting

Synergistic dispatch needs to forecast PV power, electric vehicle charging demand and normal load at 96 points per day. And the time and region distribution data of electric vehicles and PV generations are counted online, and the complementary and coordinated, and then optimize the scheduling scheme. The complementary and synergism between PV generations and electric vehicles are analysed, the scheduling scheme is optimized, peak load shifting is ultimately realized.

\section{Photovoltaic grid-connected and energy storage synergistic dispatch master station.}

In the Photovoltaic grid-connected synergistic dispatch master station, the synergistic dispatch technology mainly includes the conventional load forecasting, the electric vehicle charging demand forecasting, the forecasting of the photovoltaic power generation, the conventional scheduling strategy and so on. Through the integration of electric vehicle energy storage station and photovoltaic power generation and the main power grid ,the maximization of electric vehicles charging demand and photovoltaic power generation utilization rate is realized. The peak and the trough period are divided through analysis of the power grid load curve, the principle is that electric vehicles charge in the period of low load and discharge in the peak load at a certain charging power. 


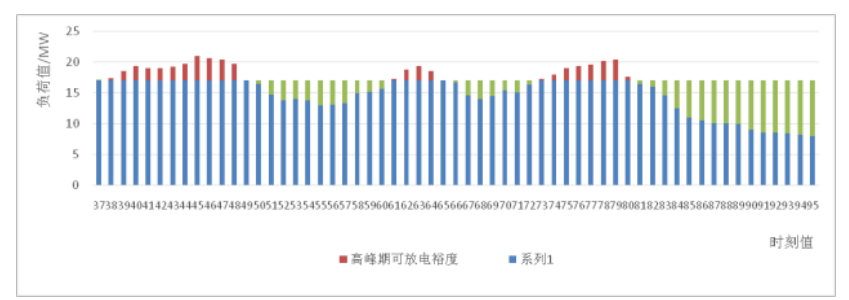

Fig. 5 the margin of charging or discharging

Modeling and maintenance of synergistic dispatch system.

Based on the CIM model in the grid platform, the form of the information sheet in the synergistic dispatch is used to establish the information model of the distributed power accessing to grid, then distributed resource substation can be added.

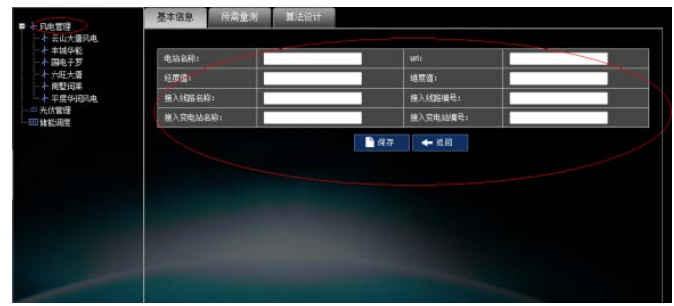

Fig.6 modeling of distributed resource substation

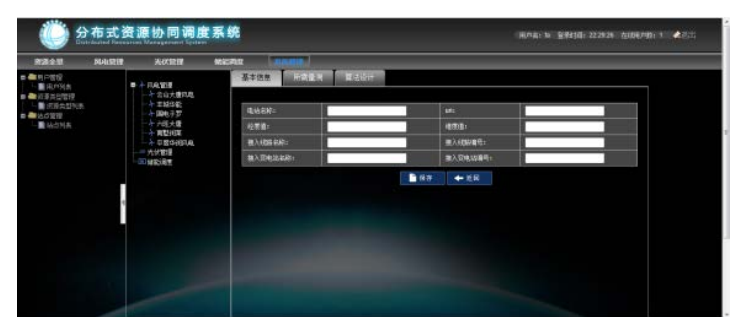

Fig.7 site maintenance

After the basic data is completed, the required measurement will be prompted. Including power station and line measurement. If the power station own data is enough to complete the calculation of power and other resources, line measurement can be ignored; if the power station own data is not enough, line data is required ,we can click on the line of measurement updates, obtaining the measurement information.

\section{Conclusions}

Renewable energy accessing to grid and synergistic dispatch management system has been applied in Qingdao power supply company dispatch center. The practice shows that the battery energy storage systems and distributed power synergistic dispatch management system can make use of synergy and complementarity of renewable energy, storage resources and the main grid, making up for the irregular and intermittent characteristics of distributed energy. Electric vehicles, photovoltaic power generation and grid coordinate with each other through their complementarity. The electric vehicle charging for electricity demand is met, improving the photovoltaic power generation efficiency and reducing power grid peak valley ratio, the economic operation of the power grid is improved.

While generating economic benefits, the system can effectively improve the power grid dispatching personnel the ability to control distributed renewable energy grid-connected. Through synergistic dispatch, energy conservation is achieved, sustainable development of green power, the improvement of distributed renewable energy share ,the transformation of economic and social development of low-carbon are promoted.

\section{References}

[1] Dayang Yu,Jun Liang,Xueshan Han,et al. Profiling the regional wind power fluctuation in China[J]. Energy Policy,2011,39(1):299-306.

[2] Dayang Yu,Xueshan Han,Jianguo Zhao. A method to assess the regional wind power fluctuation based on the meteorological observing system[J]. International Journal of Green Energy,2010,7(5):516-529.

[3] Dayang Yu,Xueshan Han. Study on the profiling of china's regional wind power fluctuation using GEOS-5 data assimilation system of national aeronautics and space administration of America[J].Automation of Electric Power Systems, 2011,35(5):77-81. 
[4] Choi J, Oh S, Horowitz R. Distributed learning and cooperative control for multi-agent systems[J]. Automatica, 2009, 45(12): 2802-2814. 